\title{
Translocation breakpoints of chromosome 1 in male carriers: clinical features and implications for genetic counseling
}

R.X. Wang, H.G. Zhang, Y. Pan, S. Chen, F.G. Yue, D.L. Zhu and R.Z. Liu

Center for Reproductive Medicine, Center for Prenatal Diagnosis, First Hospital, Jilin University, Changchun, Jilin, China

Corresponding author: R.Z. Liu

E-mail: 1rz410@126.com

Genet. Mol. Res. 15 (4): gmr.15048707

Received April 12, 2016

Accepted May 17, 2016

Published October 5, 2016

DOI http://dx.doi.org/10.4238/gmr.15048707

Copyright $($ C 2016 The Authors. This is an open-access article distributed under the terms of the Creative Commons Attribution ShareAlike (CC BY-SA) 4.0 License.

\begin{abstract}
Reciprocal translocation is closely associated with male infertility and recurrent miscarriages. Balanced reciprocal translocations associated with reproductive failures are predominantly observed on chromosome 1. Additionally, infertile male patients present a number of breakpoints throughout chromosome 1. A translocation breakpoint might interrupt the structure of an important gene, leading to male infertility. Here, we report the breakpoints on chromosome 1 translocation and the clinical features presented in carriers, to enable informed genetic counseling of these patients. Balanced reciprocal translocations were found in $1.57 \%$ of the tested patients. Among 82 patients, 23 patients $(28.05 \%)$ were carriers of the chromosome 1 translocation: 12 presented pre-gestational infertility with clinical manifestations of azoospermia or oligozoospermia, while 11 patients presented gestational infertility (able to conceive but with a tendency to miscarry or give birth to a stillborn). The breakpoint at $1 \mathrm{p} 22$ was
\end{abstract}


predominantly observed in these patients; additionally, breakpoints at $1 \mathrm{p} 31.2,1 \mathrm{p} 10$, and $1 \mathrm{q} 25$ were associated with gestational infertility. Breakpoints at 1p13, 1q12, and 1q21 were associated with pregestational infertility. These results suggested that breakpoints at $1 \mathrm{p} 32$, $1 \mathrm{p} 13$, and 1q21 were predominantly associated with pre-gestational infertility, while that at 1q25 was associated with gestational infertility. Chromosome 1 translocation carriers with infertility presenting as azoospermia or oligospermia should be counseled on chromosomal breakpoints and the different molecular technologies available to facilitate reproduction.

Key words: Male infertility; Chromosome 1; Balanced translocation; Breakpoint; Genetic counseling

\section{INTRODUCTION}

The reproductive outcomes, sperm parameters, and sperm aneuploidy in male carriers of reciprocal translocation are receiving increased attention over the past few years ( $\mathrm{Li}$ et al., 2015; Pastuszek et al., 2015; Zhang et al., 2015c). Reciprocal translocation is closely related to male infertility and recurrent miscarriage. These effects are dependent on the specific chromosomes involved in the translocation, the locations of the breaks, and the frequency of chiasmata (Vozdova et al., 2008; Harton and Tempest, 2012; Godo et al., 2013). Previous reports indicate the involvement of balanced reciprocal translocations on chromosome 1 in male infertility and recurrent miscarriages (Tharapel et al., 1985; Quan et al., 2013; Zhang et al., 2015b,c). Chromosome 1 may harbor a critical domain whose integrity is essential for male fertility (Bache et al., 2004; Paliwal et al., 2010). Infertile male patients present breakpoints throughout the length of their chromosome 1; however, specifically implicating the breakpoint located at 1q21 in the infertility (Bache et al., 2004).

Most balanced chromosomal aberrations are not associated with a clinical phenotype; however, in some male patients, one of the translocation breakpoints interrupts an important gene structure, leading to infertility (Pernice et al., 2002; Bianco et al., 2011; Harton and Tempest, 2012; Li et al., 2014). Polymorphisms at the 5,10-methylene tetrahydrofolate reductase locus, mapped on chromosome 1 at the end of the short arm (1p36.6), are associated with an increased risk of non-obstructive azoospermia (NOA) (Kim et al., 2015; Liew and Gupta, 2015). The etiology of NOA in Han Chinese men includes genetic variants at 1p13.3 and 1p36.32 (Hu et al., 2011), while a related gene at 1q42.13 is related to male fertility (Hu et al., 2014).

The aim of this study was to determine the correlation between the clinical characteristics of NOA and the carriers of translocation breakpoints on chromosome 1 . Additionally, the importance of genetic counseling for NOA patients is highlighted.

\section{MATERIAL AND METHODS}

\section{Patients}

Five thousand two hundred and thirty-five men diagnosed with infertility, or those receiving counseling for infertility due to genetic causes, were recruited from the outpatient 
clinic of the Centre for Reproductive Medicine at the First Hospital of Jilin University, Changchun, China, between July 2010 and December 2015. All patients underwent a thorough physical examination and a semen analysis, and were required to complete a detailed questionnaire pertaining to their smoking, marital status, medical histories, and working conditions. Azoospermia and oligozoospermia were defined as previously described (Zhang et al., 2015b). The study protocol was approved by the Ethics Committee of the First Hospital of Jilin University, and written informed consent was obtained from all participants.

\section{Cytogenetic analysis}

All patients were also subjected to a cytogenetic analysis. Peripheral blood $(0.5 \mathrm{~mL})$ was collected in sterile tubes containing $30 \mathrm{U} / \mathrm{mL}$ heparin. Lymphocytes were cultured in appropriate culture media (Yishengjun; Guangzhou Baidi Biotech, Guangzhou, China) for $72 \mathrm{~h}$, and subsequently treated with $20 \mu \mathrm{g} / \mathrm{mL}$ colcemid for $1 \mathrm{~h}$. G-banding of metaphase chromosomes and karyotype analysis were performed using previously published methods (Zhang et al., 2015a).

\section{RESULTS}

A total of 5235 male patients were included in this study. Conventional cytogenetic analysis revealed a reciprocal translocation in $82(1.57 \%)$ of the study participants. Of these, 23 patients $(23 / 82 ; 28.05 \%)$ were carriers of a chromosome 1 translocation. Twelve (12/23) of these patients exhibited pre-gestational infertility (clinical manifestations: azoospermia or oligozoospermia), while the remaining 11 patients exhibited gestational infertility (patients' partners are able to conceive, but have a tendency to miscarry or give birth to a stillborn). The results of a karyotype analysis of the 23 patients expressing the chromosome 1 translocation are summarized in Table 1.

Table 1. Karyotypes of chromosome 1 translocation carriers and their clinical features.

\begin{tabular}{|c|c|c|}
\hline Infertility causes & Clinical findings & Karyotype \\
\hline Pre-gestational infertility & Azoospermia or oligozoospermia & $\begin{array}{l}46, \mathrm{XYt}(1 ; 2)(\mathrm{q} 21 ; \mathrm{p} 23) \\
46, \mathrm{XYt}(1 ; 2)(\mathrm{q} 21 ; \mathrm{q} 37) \\
46, \mathrm{XYt}(1 ; 3)(\mathrm{p} 22 ; \mathrm{p} 13) \\
46, \mathrm{XYt}(1 ;)(\mathrm{p} 34 ; ; 32) \\
46, \mathrm{XYt}(1 ; 9)(\mathrm{p} 32 ; \mathrm{p} 24) \\
46, \mathrm{XYt}(1 ; 10)(\mathrm{q} 21 ; \mathrm{p} 12) \\
46, \mathrm{XYt}(1 ; 12)(\mathrm{q} 42 ; \mathrm{q} 13) \\
46, \mathrm{XYt}(1 ; 13)(\mathrm{p} 22 ; \mathrm{q} 14) \\
46, \mathrm{XYt}(1 ; 13)(\mathrm{p} 36, \mathrm{q} 32) \\
46, \mathrm{XYt}(1 ; 18)(\mathrm{p} 22 ; \mathrm{q} 21) \\
46, \mathrm{XYt}(1 ; 20)(\mathrm{p} 13 ; \mathrm{p} 11.2) \\
46, \mathrm{XYt}(1 ; 21)(\mathrm{q} 12 ; \mathrm{p} 11.2)\end{array}$ \\
\hline Gestational infertility & Normal sperm density; a history of miscarriage or stillbirth & $\begin{array}{l}46, \mathrm{XYt}(1 ; 4)(\mathrm{p} 36 ; \mathrm{q} 31) \\
46, \mathrm{XYt}(1 ; 10)(\mathrm{p} 31.2 ; \mathrm{q} 26) \\
46, \mathrm{XYt}(1 ; 11)(\mathrm{q} 42 ; \mathrm{q} 21) \\
46, \mathrm{XYt}(1 ; 12)(\mathrm{q} 42 ; \mathrm{q} 13) \\
46, \mathrm{XYt}(1 ; 12)(\mathrm{p} 34 ; \mathrm{q} 13) \\
46, \mathrm{XYt}(1 ; 13)(\mathrm{p} 22 ; \mathrm{q} 32) \\
46, \mathrm{XYt}(1 ; 13)(\mathrm{q} 25 ; \mathrm{q} 14) \\
46, \mathrm{XYt}(1 ; 14)(\mathrm{p} 36 ; \mathrm{q} 24) \\
46, \mathrm{XYt}(1 ; 18)(\mathrm{p} 32 ; \mathrm{q} 23) \\
46, \mathrm{XYt}(1 ; 19)(\mathrm{p} 10, \mathrm{q} 10) \\
46, \mathrm{XYt}(1 ; 22)(\mathrm{p} 22 ; \mathrm{q} 11)\end{array}$ \\
\hline
\end{tabular}

Genetics and Molecular Research 15 (4): gmr.15048707 
The breakpoints on chromosome 1 related to pre-gestational or gestational infertility are shown in Figure 1. The breakpoint at $1 \mathrm{p} 22$ was the most common, and was observed in 5 patients. The breakpoints at $1 \mathrm{p} 13,1 \mathrm{q} 12$, and $1 \mathrm{q} 21$ were related to pre-gestational infertility, while the breakpoints at $1 \mathrm{p} 31.2,1 \mathrm{p} 10$, and $1 \mathrm{q} 25$ were related to gestational infertility. On the other hand, the breakpoints at $1 \mathrm{p} 36,1 \mathrm{p} 34,1 \mathrm{p} 32,1 \mathrm{p} 22$, and $1 \mathrm{q} 42$ were related to both pregestational and gestational infertility (Table 2 ).

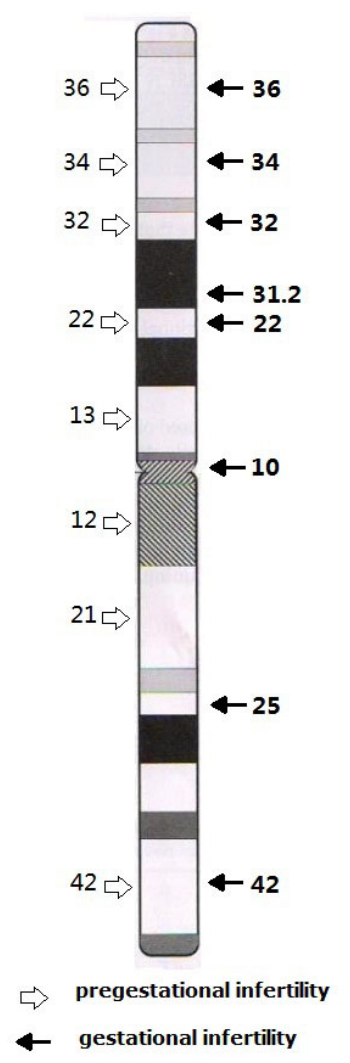

Figure 1. Breakpoints on chromosome 1 related to pre-gestational or gestational infertility.

\section{Table 2. Incidence of breakpoints on chromosome 1.}

\begin{tabular}{l|c|c|c}
\hline Breakpoints & Number of patients expressing pre-gestational infertility & Number of patients with gestational infertility & Total (\%) \\
\hline p36 & 1 & 2 & $3(13.04 \%)$ \\
\hline p34 & 1 & 1 & $2(8.70 \%)$ \\
\hline p32 & 1 & 1 & $2(8.70 \%)$ \\
\hline p31.2 & 3 & 1 & $1(4.35 \%)$ \\
\hline p22 & 1 & 2 & $5(21.74 \%)$ \\
\hline p13 & & & $1(4.35 \%)$ \\
\hline p10 & 1 & 1 & $1(4.35 \%)$ \\
\hline 12 & 3 & & $1(4.35 \%)$ \\
\hline q21 & & 1 & $3(13.04 \%)$ \\
\hline 25 & 1 & 2 & $1(4.35 \%)$ \\
\hline q42 & & & $3(13.04 \%)$ \\
\hline
\end{tabular}

Genetics and Molecular Research 15 (4): gmr.15048707 


\section{DISCUSSION}

Karyotype analysis remains the most powerful and affordable among all molecular technologies used for the diagnosis of disease; therefore, this method continues to have wide application in this field (Pasquier et al., 2016). Carriers of reciprocal translocations, while normal phenotypically, may experience reduced fertility, spontaneous abortions, or birth defects (Harton and Tempest, 2012). Reciprocal translocations are found at a frequency of $0.9 / 1000$ in newborns. Previous studies have reported that the presence of translocations alters the process of spermatogenesis. Reciprocal translocations are often detected in infertile men (Stouffs et al., 2014). The incidence of reciprocal translocation carriers is seven times higher than that of a newborn series (Ferlin et al., 2007). Additionally, the incidence of balanced reciprocal translocation is (reportedly) the highest on chromosome 1 in couples with reproductive failure (Quan et al., 2013; Zhang et al., 2015b). In this study, reciprocal translocation was identified in $82(1.57 \%)$ infertile men, among who $23(28.05 \%, 23 / 82)$ were carriers of the chromosome 1 translocation. The major limitation of this study is the small number of carriers of the chromosome 1 translocation; moreover, the molecular effect of this translocation was not investigated in this study, necessitating further research.

Balanced chromosomal translocations are associated with an increased risk of pregnancy loss, fetal death, and male infertility (Godo et al., 2013). The latter is divided into two types of reproductive failure: pre-gestational and gestational infertility. In this study, the breakpoints on chromosome 1 were found to be associated with pre-gestational or gestational infertility. The breakpoints at $1 \mathrm{p} 13,1 \mathrm{q} 12$, and 1q21 were associated with pre-gestational infertility, whereas those at $1 \mathrm{p} 31.2,1 \mathrm{p} 10$, and $1 \mathrm{q} 25$ were associated with gestational infertility. However, the breakpoints at $1 \mathrm{p} 36,1 \mathrm{p} 34,1 \mathrm{p} 32,1 \mathrm{p} 22$, and $1 \mathrm{q} 42$ were associated with both, pre-gestational and gestational infertility. Among the latter, the breakpoint at $1 \mathrm{p} 22$ was identified in a majority of the patients. Similarly, Kim et al. (2011) reported a correlation between the breakpoints at $1 \mathrm{p} 32,1 \mathrm{p} 22.3,1 \mathrm{p} 13,1 \mathrm{q} 41$, and $1 \mathrm{q} 42$ and impaired spermatogenesis, as well as an association between 1p13 and 1q21 and recurrent abortion. An analysis of related literature published in recent years revealed a close association between breakpoints on chromosome 1 translocation carriers and azoospermia, male infertility, and reproductive failure. The karyotypes of, and breakpoints on, chromosome 1, and their related clinical symptoms, are summarized in Table 3.

\begin{tabular}{|c|c|c|c|}
\hline Karyotype & Breakpoints & Clinical findings & Reference \\
\hline$t(1 ; 3)$ & $1 \mathrm{p} 32 ; 3 \mathrm{q} 29$ & Oligozoospermia & Vozdova et al., 2013 \\
\hline$t(1 ; 7)$ & $1 \mathrm{p} 32 ; 7 \mathrm{q} 22$ & Severe oligozoospermia & Vozdova et al., 2013 \\
\hline $\mathrm{t}(1 ; 19)$ & $1 \mathrm{p} 13 ; 13.3$ & Male infertility & Mierla et al., 2014 \\
\hline$t(1 ; 22)$ & $1 \mathrm{q} 11 ; 1 \mathrm{p} 11$ & Azoospermia & Lorda-Sanchez et al., 2001 \\
\hline $\mathrm{t}(1 ; 15)$ & $1 \mathrm{q} 11 ; 15 \mathrm{p} 11$ & Azoospermia & López-Ginés et al., 1987 \\
\hline $\mathrm{t}(1 ; 21)$ & $1 \mathrm{q} 11 ; 21 \mathrm{p} 13$ & Azoospermia & Vialard et al., 2006 \\
\hline $\mathrm{t}(1 ; 22)$ & $1 \mathrm{q} 11 ; 22 \mathrm{p} 11$ & Azoospermia & Vialard et al., 2006 \\
\hline $\mathrm{t}(1 ; 9)$ & $1 \mathrm{q} 11 ; \mathrm{p} 13$ & Male infertility & Mierla et al., 2014 \\
\hline $\mathrm{t}(1 ; 17)$ & $1 \mathrm{q} 21 ; 17 \mathrm{p} 12$ & Severe oligozoospermia & Amouri et al., 2014 \\
\hline $\mathrm{t}(1 ; 13)$ & $1 \mathrm{q} 24 ; 13 \mathrm{q} 10)$ & Male infertility & Sazci et al., 2005 \\
\hline$t(1 ; 6)$ & $1 \mathrm{q} 25 ; 6 \mathrm{q} 16$ & Reproductive failure & GadaSaxena et al., 2012 \\
\hline $\mathrm{t}(1 ; 2)$ & $1 \mathrm{q} 32.1 ; 2 \mathrm{q} 11.2$ & Oligozoospermia & Vozdova et al., 2013 \\
\hline $\mathrm{t}(1 ; 13)$ & $1 \mathrm{q} 42 ; 13 \mathrm{q} 14$ & Oligozoospermia & Vozdova et al., 2013 \\
\hline $\mathrm{t}(1 ; 4)$ & $1 \mathrm{q} 43 ; 1 \mathrm{q} 13$ & Male infertility & Mierla et al., 2014 \\
\hline$t(1 ; 6)$ & $1 \mathrm{q} 44 ; 6 \mathrm{p} 11$ & Abortion & Vozdova et al., 2013 \\
\hline $\mathrm{t}(1 ; 14)$ & $1 \mathrm{q} 44 ; 1 \mathrm{q} 22$ & Oligozoospermia & Vozdova et al., 2013 \\
\hline $\mathrm{t}(1 ; 14)$ & $1 \mathrm{q} 44 ; 14 \mathrm{q} 11.2$ & Azoospermia & Dul et al., 2012 \\
\hline
\end{tabular}

Genetics and Molecular Research 15 (4): gmr.15048707 
In total, breakpoints at $1 \mathrm{p} 32,1 \mathrm{p} 13$, and $1 \mathrm{q} 21$ are predominantly associated with pre-gestational infertility, while the breakpoint at 1q25 is associated with gestational infertility.

Carriers of balanced translocations must receive appropriate counseling to appraise them of suitable reproductive options (Zhang et al., 2015b). Patients with pre-gestational infertility related to azoospermia or oligozoospermia must be counseled regarding chromosomal breakpoints, in vitro fertilization/intracytoplasmic sperm injection, or microdissection testicular sperm extraction. On the other hand, patients with gestational infertility should be counseled regarding prenatal testing or pre-implantation genetic diagnosis, as these patients are at an increased risk of implantation failure, miscarriage, or delivery of affected offspring (Vozdova et al., 2013).

In conclusion, balanced reciprocal translocation was observed in $1.57 \%$ of all tested infertile male patients. Among these, 23 patients $(28.05 \%)$ were carriers of the chromosome 1 translocation, 12 expressing pre-gestational infertility and 11 presenting gestational infertility. Breakpoints at $1 \mathrm{p} 22$ were predominantly associated with male infertility. Breakpoints at $1 \mathrm{p} 32,1 \mathrm{p} 13$, and $1 \mathrm{q} 21$ were associated with pre-gestational infertility, while those at $1 \mathrm{q} 25$ were correlated with gestational infertility. Carriers of chromosome 1 translocation with pregestational or gestational infertility should be counseled on chromosomal breakpoints and the different molecular technologies available to facilitate reproduction.

\section{Conflicts of interest}

The authors declare no conflict of interest.

\section{ACKNOWLEDGMENTS}

We express our sincere gratitude to the staff of the Genetics Laboratory, Center for Prenatal Diagnosis, First Hospital, Jilin University, for their support. Research supported by the National Natural Science Fund (\#81471515).

\section{REFERENCES}

Amouri A, Hammami W, Kilani O, Bouzouita A, et al. (2014). Chromosomal evaluation in a group of Tunisian patients with non-obstructive azoospermia and severe oligozoospermia attending a Tunisian cytogenetic department. $C$. $R$. Biol. 337: 223-228. http://dx.doi.org/10.1016/j.crvi.2014.02.006

Bache I, Assche EV, Cingoz S, Bugge M, et al. (2004). An excess of chromosome 1 breakpoints in male infertility. Eur. J. Hum. Genet. 12: 993-1000. http://dx.doi.org/10.1038/sj.ejhg.5201263

Bianco B, Christofolini D, Gava M, Mafra F, et al. (2011). Severe oligospermia associated with a unique balanced reciprocal translocation t(6;12)(q23;q24.3): male infertility related to t(6;12). Andrologia 43: 145-148. http://dx.doi. org/10.1111/j.1439-0272.2009.01020.x

Dul EC, van Echten-Arends J, Groen H, Dijkhuizen T, et al. (2012). Chromosomal abnormalities in azoospermic and nonazoospermic infertile men: numbers needed to be screened to prevent adverse pregnancy outcomes. Hum. Reprod. 27: 2850-2856. http://dx.doi.org/10.1093/humrep/des222

Ferlin A, Raicu F, Gatta V, Zuccarello D, et al. (2007). Male infertility: role of genetic background. Reprod. Biomed. Online 14: 734-745. http://dx.doi.org/10.1016/S1472-6483(10)60677-3

Gada Saxena S, Desai K, Shewale L, Ranjan P, et al. (2012). Chromosomal aberrations in 2000 couples of Indian ethnicity with reproductive failure. Reprod. Biomed. Online 25: 209-218. http://dx.doi.org/10.1016/j.rbmo.2012.04.004

Godo A, Blanco J, Vidal F and Anton E (2013). Accumulation of numerical and structural chromosome imbalances in spermatozoa from reciprocal translocation carriers. Hum. Reprod. 28: 840-849. http://dx.doi.org/10.1093/humrep/des431

Harton GL and Tempest HG (2012). Chromosomal disorders and male infertility. Asian J. Androl. 14: 32-39. http://dx.doi. org/10.1038/aja.2011.66

Genetics and Molecular Research 15 (4): gmr.15048707 
Hu Z, Xia Y, Guo X, Dai J, et al. (2011). A genome-wide association study in Chinese men identifies three risk loci for non-obstructive azoospermia. Nat. Genet. 44: 183-186. http://dx.doi.org/10.1038/ng.1040

$\mathrm{Hu} \mathrm{Z}$, Li Z, Yu J, Tong C, et al. (2014). Association analysis identifies new risk loci for non-obstructive azoospermia in Chinese men. Nat. Commun. 5: 3857. http://dx.doi.org/10.1038/ncomms4857

Kim JW, Chang EM, Song SH, Park SH, et al. (2011). Complex chromosomal rearrangements in infertile males: complexity of rearrangement affects spermatogenesis. Fertil. Steril. 95: 349-352. http://dx.doi.org/10.1016/j. fertnstert.2010.08.014

Kim SY, Lim JW, Kim JW, Park SY, et al. (2015). Association between genetic polymorphisms in folate-related enzyme genes and infertile men with non-obstructive azoospermia. Syst. Biol. Reprod. Med. 61: 286-292.

Li L, Chen H, Yin C, Yang C, et al. (2014). Mapping breakpoints of a familial chromosome insertion (18,7) (q22.1; q36.2q21.11) to DPP6 and CACNA2D1 genes in an azoospermic male. Gene 547: 43-49. http://dx.doi.org/10.1016/j.gene.2014.06.007

Li LL, Dong Y, Wang RX, An N, et al. (2015). Sperm aneuploidy and implications for genetic counseling in a pedigree of three $\mathrm{t}(1 ; 3)$ balanced translocation carriers. Genet. Mol. Res. 14: 5003-5009. http://dx.doi.org/10.4238/2015.May.12.3

Liew SC and Gupta ED (2015). Methylenetetrahydrofolate reductase (MTHFR) C677T polymorphism: epidemiology, metabolism and the associated diseases. Eur. J. Med. Genet. 58: 1-10. http://dx.doi.org/10.1016/j.ejmg.2014.10.004

López-Ginés C, Gil R, Gregori-Romero M and Pellin A (1987). An azoospermic male with reciprocal translocation $\mathrm{t}(1 ; 15)$ (q11;p11). Hum. Genet. 77: 294. http://dx.doi.org/10.1007/BF00284491

Lorda-Sanchez I, Tejedor C, Sanz R, Rodriguez de Alba M, et al. (2001). A maternal inherited translocation $\mathrm{t}(1 ; 22)$ (q11;p11) in two infertile brothers. Genet. Couns. 12: 95-100.

Mierla D, Jardan D and Stoian V (2014). Chromosomal abnormality in men with impaired spermatogenesis. Int. J. Fertil. Steril. 8: 35-42.

Paliwal P, Sharma A, Sahoo J and Ammini AC (2010). An unusual association of hypospadias with partial deletion of chromosome 1q. Fertil. Steril. 93: 2413. http://dx.doi.org/10.1016/j.fertnstert.2009.12.003

Pasquier L, Fradin M, Chérot E, Martin-Coignard D, et al. (2016). Karyotype is not dead (yet)! Eur. J. Med. Genet. 59: 11-15. http://dx.doi.org/10.1016/j.ejmg.2015.11.016

Pastuszek E, Kiewisz J, Kulwikowska PM, Lukaszuk M, et al. (2015). Sperm parameters and DNA fragmentation of balanced chromosomal rearrangements carriers. Folia Histochem. Cytobiol. 53: 314-321. http://dx.doi.org/10.5603/fhc.a2015.0032

Pernice F, Mazza G, Puglisi D, Luppino MG, et al. (2002). Nonrobertsonian translocation t(6;11) is associated with infertility in an oligoazoospermic male. Fertil. Steril. 78: 192-194. http://dx.doi.org/10.1016/S0015-0282(02)03180-1

Quan Q, Li TJ, Ding XP, Wei J, et al. (2013). Infertility caused by male partners with genetic defects in Sichuan Province of China. Genet. Mol. Res. 12: 6512-6520. http://dx.doi.org/10.4238/2013.December.11.2

Sazci A, Ercelen N, Ergul E and Akpinar G (2005). Male factor infertility associated with a familial translocation $\mathrm{t}(1 ; 13)$ (q24;q10). Fertil. Steril. 83: 1548-1550. http://dx.doi.org/10.1016/j.fertnstert.2004.10.055

Stouffs K, Seneca S and Lissens W (2014). Genetic causes of male infertility. Ann. Endocrinol. 75: 109-111. http://dx.doi. org/10.1016/j.ando.2014.03.004

Tharapel AT, Tharapel SA and Bannerman RM (1985). Recurrent pregnancy losses and parental chromosome abnormalities: a review. Br. J. Obstet. Gynaecol. 92: 899-914. http://dx.doi.org/10.1111/j.1471-0528.1985.tb03069.x

Vialard F, Nouchy M, Malan V, Taillemite JL, et al. (2006). Whole-arm translocations between chromosome 1 and acrocentric $\mathrm{G}$ chromosomes are associated with a poor prognosis for spermatogenesis: two new cases and review of the literature. Fertil. Steril. 86: 1001. http://dx.doi.org/10.1016/j.fertnstert.2006.01.061

Vozdova M, Oracova E, Horinova V and Rubes J (2008). Sperm fluorescence in situ hybridization study of meiotic segregation and an interchromosomal effect in carriers of t(11;18). Hum. Reprod. 23: 581-588. http://dx.doi. org/10.1093/humrep/dem345

Vozdova M, Oracova E, Kasikova K, Prinosilova P, et al. (2013). Balanced chromosomal translocations in men: relationships among semen parameters, chromatin integrity, sperm meiotic segregation and aneuploidy. J. Assist. Reprod. Genet. 30: 391-405. http://dx.doi.org/10.1007/s10815-012-9921-9

Zhang HG, Liu XY, Hou Y, Chen S, et al. (2015a). Reproductive outcome of a case with familial balanced translocation $\mathrm{t}(3 ; 6)$ : implications for genetic counseling. Genet. Mol. Res. 14: 2809-2815. http://dx.doi.org/10.4238/2015.March.31.11

Zhang HG, Wang RX, Li LL, Sun WT, et al. (2015b). Male carriers of balanced reciprocal translocations in Northeast China: sperm count, reproductive performance, and genetic counseling. Genet. Mol. Res. 14: 18792-18798. http:// dx.doi.org/10.4238/2015.December.28.28

Zhang M, Fan HT, Zhang QS, Wang XY, et al. (2015c). Genetic screening and evaluation for chromosomal abnormalities of infertile males in Jilin Province, China. Genet. Mol. Res. 14: 16178-16184. http://dx.doi.org/10.4238/2015. December.8.7

Genetics and Molecular Research 15 (4): gmr.15048707 